


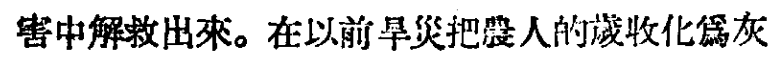

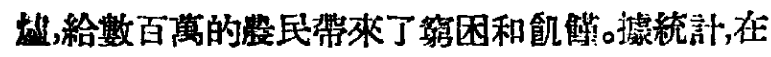
大革命前的最後六十五年中，沿伦霜少州河的地區 會遭遇到二十次的旱災，常学位部多鄉村的農民 全部遭到了餓整。偉大的俄羅断作家 $\Omega$ - 托爾斯秦 在1873年所舁的一篇 “撒爾是斯分的彾鳀” 的記述 文中說: “目前已經不單純是收成不好, 而是彾矔

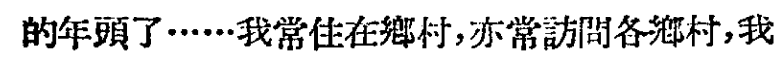

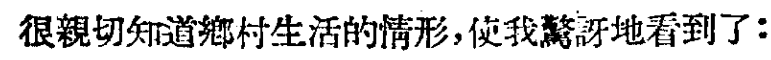

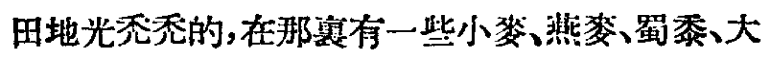

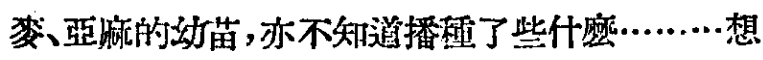

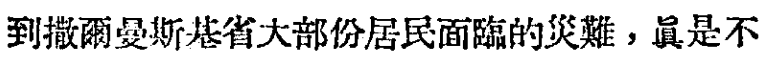
寒而福…....”

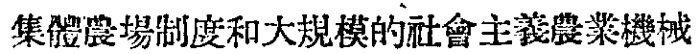
化克服了困難，提高了伏爾为河左岸田地的收成。 將來以占比雪夫水力發電站管基礎，惯行廣泛地

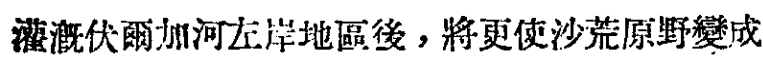
肥沃田地，給予社會經沾全面發展的一個䉼的推

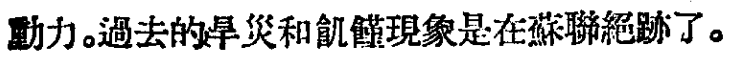

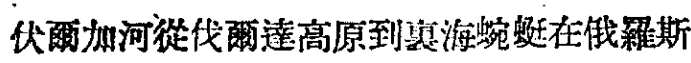

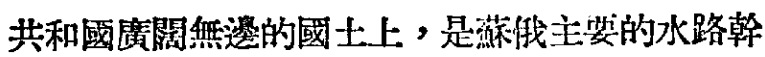

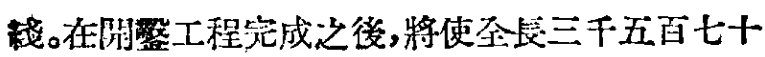
餘公里的伏爾加河有三千公里以上可容巨型棆船

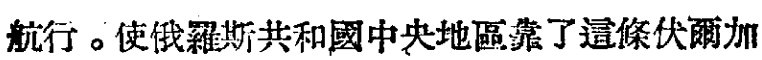
河與波羅的海間的莫斯科蓮河，聯紹白海與波羅

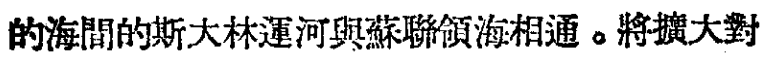
'國民經湾糧食，木材，石油以及其他货物上的蓮輸。

㩐聯部長會議决定在本年度邽始占比雪夫水 力中心的建钤, 並顷定在1955年全部完工,它的進 行速度正如它規模的偉大, 是在過去貄築䃼史上 從不會有過的。下面的記錄数字將表明它規模之 大和進行速度之快的一般：

需要完成一檍五干萬立方公尺的土方工作， 打包六百萬立方公尺的三合士。每小時在建築上 必須完成一千立方公尺以上的銅骨水泥的打包工 作，每小時要從事於鳌城一千立方公尺土方的工 作本。(用强大的電力閶整機配以其他的技術每小 时的工作率是 $200-300$ 立方公尺的土方)。

第二個在進行建設中的水力發電站是斯大林

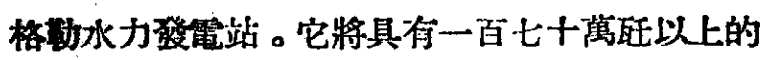
固定张電能力, 而它在水位正: 常年份的發電量亦 將接近一百䈍䏕時。
斯大林格勒和占比雪夫同樣是伏爾加河上的

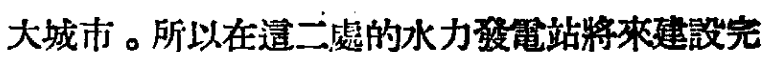
成啳,將成第伏爾胁河上的二個巨人。

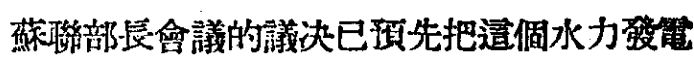
站的發電量作如下的分配：

40億酩時分配給莫斯科一一薢聯的首都。

12億率時分配給中央黑上地區。

28億䣨時分配給斯大林格勤、薩拉拖大断基 和阿斯脫拉哈斯基各地區。

20 億站時分配到沿伏爾 加河和沿 就海的區 域。

斯大林格勤水力發電站和占比雪夫水力發電 站一粶，亦祇是斯大林格勒水力中心建設之中的 一個主骵建設，此外還有巨型蓄水池，唧水站等的 建筑。斯大林格勒水力中心的第一個任務是在鹳

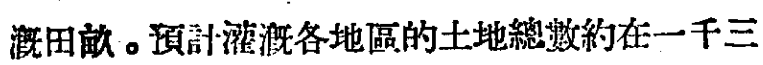

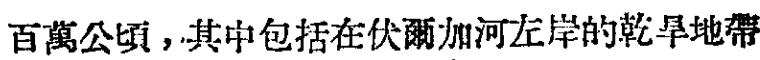

一百五十萬公頃 ; 在敦海北部伏爾加河與鳥 拉爾河之間的荒原和牛荒原——約六百萬頃；在 薩啷賓斯基低地，黑上地區和諾加依斯基草原一 一䄪五百五十葛公顷。

斯大林格勤水力和心的第二個任移是要算加 對中央地區的電力供然心。斯大林格勒的電力將在

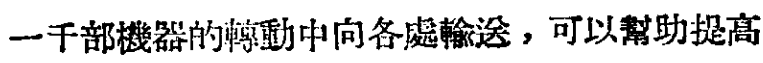
城方的生活方式到新的、更高的文化階段; 更持久 地深入到中央地區的、沿伙爾拗河地區的、中央黑 土地區的集繒震場和國營费場一它們的生產和 文化的生活中。

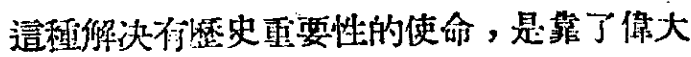

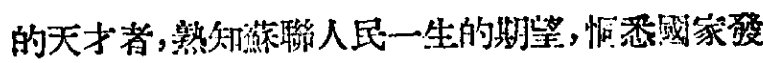
展的前途,深信䰻聯人民的力量,一一落維埃人民 所敬受的領袖和梁師斯大林，才敢提出，才放毅然 執行的。

葆聯部長會議决議在 1951年開始建設斯大林 格勤水力磁笛站, (按: 現在已在僬行踏勘, 测量等 籍借工作)並颃定在 1956 年完成和管際上完全的 胙用。其間進行的速度將是資本主義國家從任何 ，一點不能相比，谌至是不能夢想到的。

下面的數字記錄將表明其規模之大與進行速 鹿之快的一般:

要切斷六億立方公尺的土方的土地, 打包七 百萬立方公尺的三合土和銅骨水泥; 三合土打包 
工作規定每天不能少於一萬立方公尺，三合上原 料一项的供應海天須有二十四次满載量的火車來 担任。

斯大林格勤是英雄的战书，蔡聯人民曾經在 這赛獲得了二次歷史上戰等方面的勝利; 從事斯 大林格勤水力中心建設的建筑人員將要把道種歷

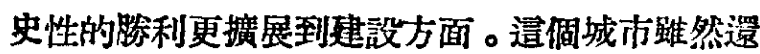
在治療鄀特勤匪徒所帶桃的野獸般的傷害, 却已

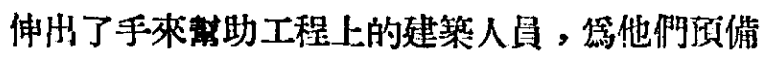
好了住宿, 倜人用品, 建築枌料, 還有一部份的工 作幹部。每倜建築人旦都準借好在克服工程上的 困難一方面要向保衛察里津和斯大林格勤二次戰 役中的英雄, 和有名的斯大林格勒拖拉機做的勞 動先進者，以及戰挠的建設战门渶雄學替。

第三倜要建設的水力發電站是卡霍夫卡水力 墢電站・卡霍夫卡是在第票伯河上的一個战门j。在 戰前，蘚聯就會在第聂任河建設了一個第是伯水 力發電站，所以卡霍夫卡水力狆電站就將成第第 伯河上第二個水力發電站了。隨客這倜水力發 電站的建设同時進行的, 還有土唯曼和南点克蘭 與北克里米亞二保大運河的阙整以及航行開門，

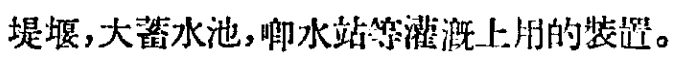

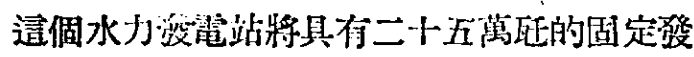
雪能力, 它在水位正常的年份的綮管量將是十二 境跴時。项定將以牛數以上的發電量利用在農業

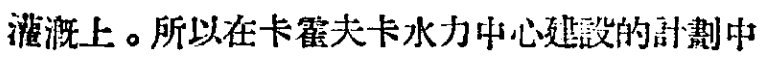
裂建筑一储容量一百四十億立方公尺的巨型蓄水 池。

卡霍夫卡水力發需站和南㿝克蘭與北克里米 亞運河將對烏克蘭的赫爾松少，查波洛什尛和尼 占拉也夫省的乾枯地區供給水鿌。將装望現灌既

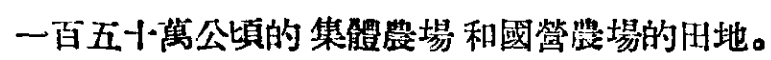
並、且預計全部水量可供灌溉一百七十萬公頃的土 地。而第耷伯河上的二大水力發電站總共將可供 給三百二十萬公頃上地的水利淮溉。

在南烏 克蘭和北克里 米亞的集候是温嗳的。 一年之中有 280-300 天都不是過很冷的天籍, 夏 天很乾燥, 有很强烈的陽光。所有這些條件都是很

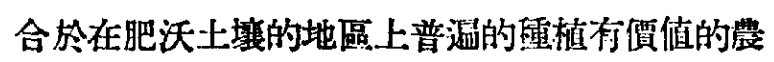
紊物, 呚如說, 棉花就是需要温䁔的氣候和陽光。

可是怙旱的現象限制了在南烏克蘭和北克里 米亞地翼耕種的可能性。在春季和夏季的時期队
只降下很少的雨水量。瀑度的不足減低了田地的 肥沃, 有時更常常危害了一年的筬收。

绿称政府在大革命之後就简多次設法與怙早 网爭。譬如, 克里米亞在 1935 年所灌溉的土地已比 大革命前多了二倍以上。這次大戰後, 在筫行斯大 林改造自然計劃的號召下, 点克蘭和克里米亞的

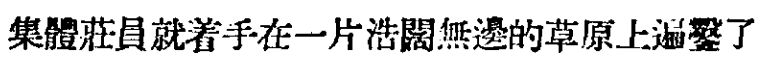
數百個池塘和水槽以及閩造讙林地區, 來改進灌

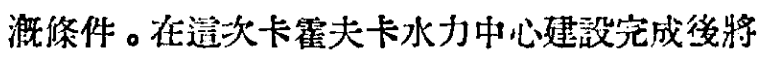
更澈底的和永世的在這個地區消隇枯旱現象。

先進的俄羅斯科學家在沙皇時代亦會提州了

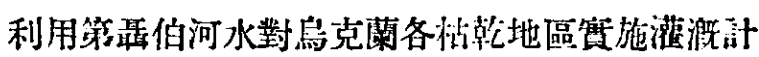
劃。然而在專䟝政治的情况下，他們的募想沒有能

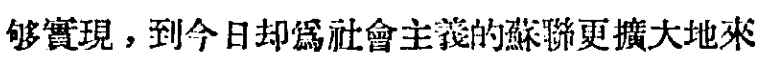
完成了。

南烏 克洅速河與北克里米亞浑河是相衡接 的,它师的總長從查波洛什省到基爾赤共計 550 公 里。在南岳克蘭運河新阿斯卡尼亞處更另有一你 60 公里舆的運河聯接卡霍夫卡大蓄水池。

卡霍夫卡水力中心建設已决定於 1951 年间

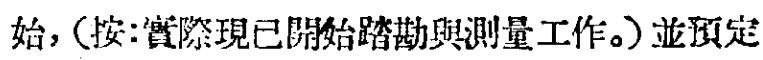
在1956年完成卡霍夫卡水力倠電站, 1957年完成 遇河, 大蓞水池, 哪水站等全部的建設。

下而的數字紀錄將表明其規模之一般:

装完成媒築約二百萬立方公尺的三合土打包

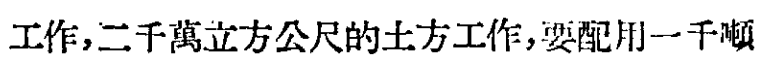
的銅骨水泥。常年建設第䨿伯水力發電站洔，打包 三合上的斯量是一百二十一䓪立方公尺。可是卡霍

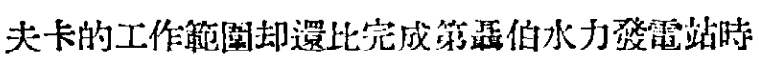
的工作範湋这大了。

在上述的三大水力發電站和二大運河的建设

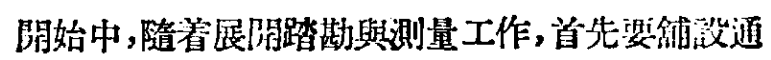
達工作現场的鐵路支綫和平坦公路, 在沿河建築 碼嘼, 以利建設材料的運輸, 在工作現場遭要得立

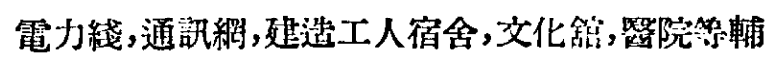
助性之建設, 以利工程之阴展。

蘇聯政府的這一些世界性 與捱史性的建設的決 議, 得到了全蘶聯人民熱烈的支持。特别是在各大 企業工激的管動工人和各建設地區的集體農場的

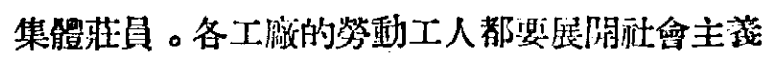

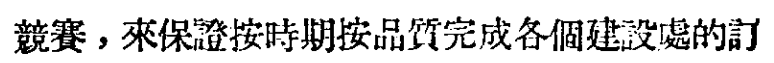
貨和一切工程上的需要。全體集鲭莊員更明確表 


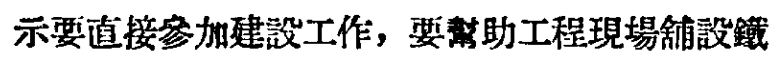
路, 建築公路等一切的工程 。他們所以都表示得 如此的䟞躍。一方面是因签他們猺儌自己的咀國, 自己的政府有遭樣空前的，偉大的建設决議，另 一方面，亦是因仵他們知道得很明白，他們的光策 的工作將替他們自己在生活上起突進的變化。這 些建設是蘇聯人民的建設,

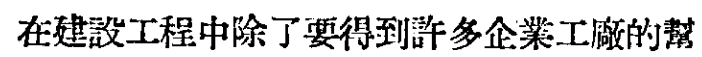
助外，還有各學校亦將䇾趣設處淮储大裂伍的專
阴人材。像占比等夫工程㦛院更委礼古比雪夫水 力建設處要谓他們在工程中給年寢的專家門從事 望習。

每一一㗍在從事逪些貄設工程的建策人員都感 到㶵比的光榮柬学握他們的工作, 在共產主蕂的 天才建筑師澌大林同志的鼓舞和領䆃之下，大家 都堅誓要在規定的期限內來完成這些歷史性的任 移,在六十年代的中柴,我門將在譄地球上看到了 這些造福人蒘的建設的出現!

\section{趋忠堯教授等獲得自由回到祖國 在穗談被美帝迫害經過}

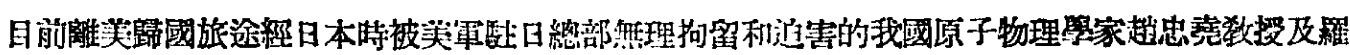

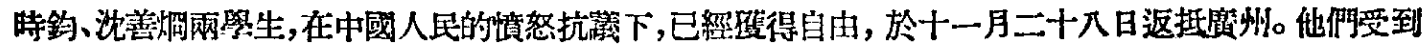

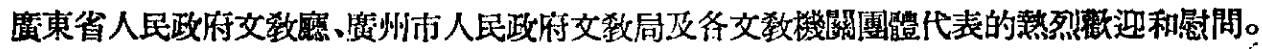

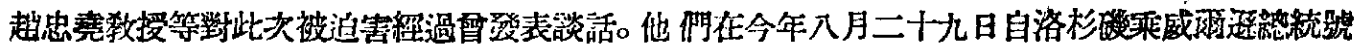

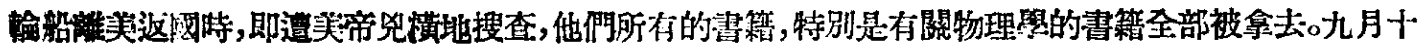

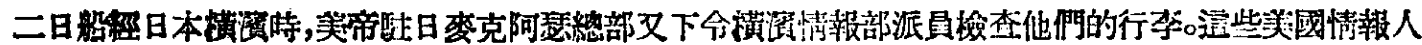

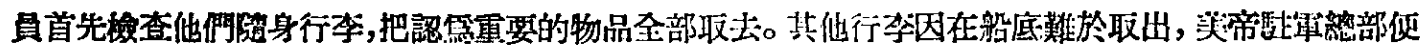

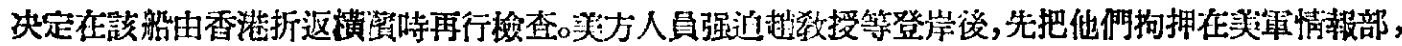
深夜十二洔移至東京中野美軍監獄,翌晨又轉移到巢鸭監狺(這是拘留日本戰犯的地方)中的 ‘中國犯人

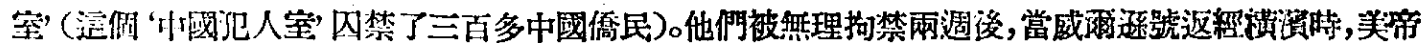
駀軍檢查了他們行李，因找不到藉口，即將他們移至國民黨駐日代表團䎶禁。直至十一月十五日，佂中國

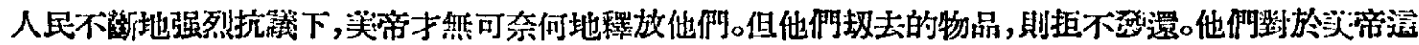
種無理泊悎，表示㒖分㥽概。

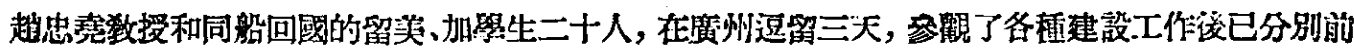

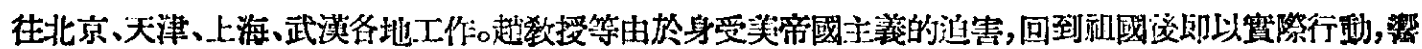

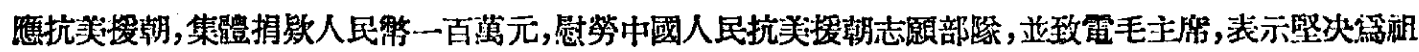

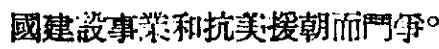

(新華鿊程)

\section{美國‘救濟物資’殺人}

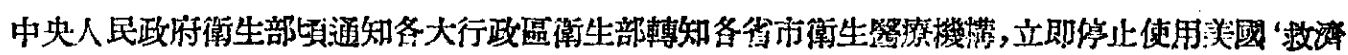

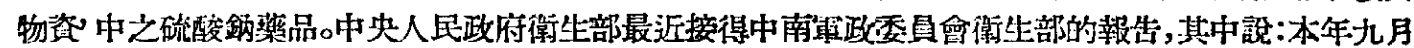

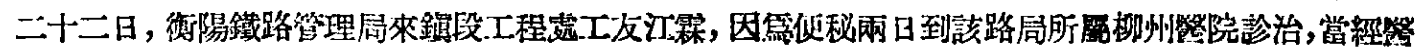

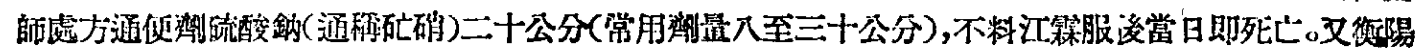

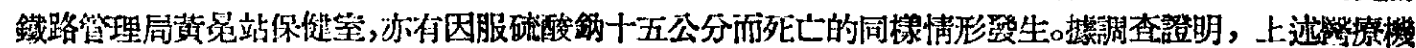

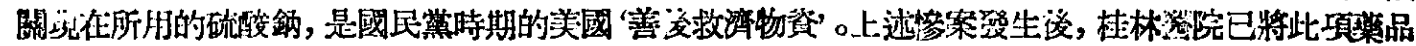

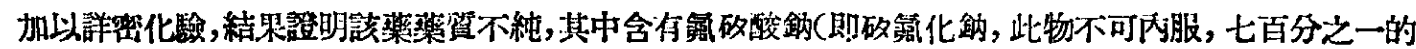

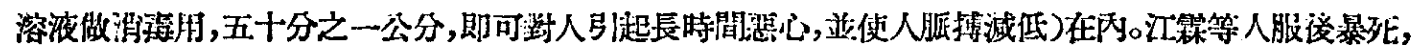

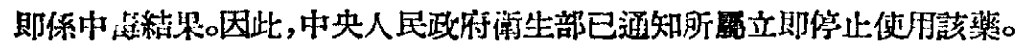

（新菬流稿） 